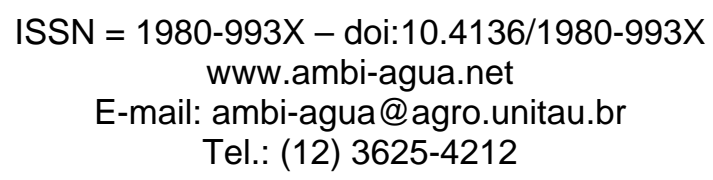

\title{
Análise da precipitação e sua influência na ocorrência de incêndios florestais no Parque Nacional Serra de Itabaiana, Sergipe, Brasil (doi:10.4136/ambi-agua.180)
}

\author{
Benjamin Leonardo Alves White ${ }^{1}$; Adauto de Souza Ribeiro ${ }^{2}$ \\ ${ }^{1}$ Programa Regional de Desenvolvimento e Meio Ambiente (PRODEMA), Universidade Federal de Sergipe \\ E-mail: benjmk@hotmail.com \\ ${ }^{3}$ Departamento de Biologia, Universidade Federal de Sergipe - Departamento de Biologia (CCBS) \\ E-mail: adautosr@ufs.br
}

\section{RESUMO}

Este trabalho teve como objetivo verificar a influência da variável climática precipitação na ocorrência de incêndios florestais, dentro do Parque Nacional Serra de Itabaiana. Para tanto, foram obtidos os dados de precipitação para o município de Itabaiana e os de ocorrência de incêndios florestais dentro do Parque, para o período de 10 anos (1999-2008). Inicialmente, os dados de precipitação foram agrupados pela Análise de Variância, de acordo com os meses do ano e, em seguida, correlacionados com a quantidade de registro de incêndios florestais, pelo coeficiente de correlação de Pearson. Para verificar a significância da correlação obtida, esta foi aplicada ao teste de significância " $t$ ". De acordo com os resultados obtidos, os meses de novembro e dezembro formaram o grupo com os menores valores de precipitação anual, enquanto os meses de maio, junho e julho representaram o grupo com os maiores valores. Correlacionando a precipitação com a quantidade de incêndios, foi obtida uma correlação negativa e significativa $(r=-0,61, p=0,03)$. Entretanto, os meses que formaram o grupo mais seco não foram os que apresentaram maior ocorrência de incêndios.

Palavras-chave: Condições meteorológicas; fogo; unidades de conservação.

\section{Rainfall analysis and its influence in forest fire occurrence in the Serra de Itabaiana National Park, Sergipe, Brazil}

\begin{abstract}
The objective of this research was to verify the influence of the climatic variable precipitation in the forest fire occurrence at the National Park Serra de Itabaiana. For this propose, precipitation data for the Itabaiana county, and forest fire occurrence data inside the Park were analyzed for a period of 10 years (1999-2008). Initially, the precipitation data had been grouped using Analysis of Variance considering the months of the year and, after that, a Pearson's coefficient of correlation was performed between precipitation data and number of registered forest fires. The " $\mathrm{t}$ " test of significance was applied to verify the correlation significance. The results showed that the months of November and December formed the group with lower annual precipitation values, while the months of May, June and July represented the group with highest values. Correlating the precipitation with the number of fires, a negative and significant correlation coefficient $(\mathrm{r}=-0.61, \mathrm{p}=0.03)$ was obtained. However, the driest months did not have the highest number of fire occurrences.
\end{abstract}

Keywords: Climate; fire; conservation units. 
WHITE, B. L. A.; RIBEIRO, A. S. Análise da precipitação e sua influência na ocorrência de incêndios florestais no Parque Nacional Serra de Itabaiana, Sergipe, Brasil. Ambi-Agua, Taubaté, v. 6, n. 1, p. 148-156, 2011.

\section{INTRODUÇÃO}

Os incêndios são uma das maiores ameaças aos reflorestamentos e florestas nativas do planeta, causando bilhões de dólares em prejuízo todos os anos. Há décadas, os incêndios florestais vêm sendo estudados, entretanto, à medida que as florestas passaram a ganhar maior importância econômica, começaram a surgir pesquisas e trabalhos mais específicos com o objetivo de reduzir os impactos negativos causados pelo fogo.

A ocorrência dos incêndios está sempre associada a períodos sem chuva. Existe uma forte correlação entre ocorrência de grandes incêndios e prolongados períodos de seca. Longos períodos de estiagem afetam o potencial de propagação dos incêndios de diversas maneiras, principalmente pela secagem progressiva do material combustível morto, podendo, inclusive, afetar o teor de umidade da vegetação verde. Isso aumenta a probabilidade de ignição e a facilidade de propagação do incêndio (Soares e Batista, 2007).

Sendo assim, a precipitação é fator essencial na redução do potencial de ocorrência e propagação dos incêndios, chegando até mesmo a zero, dependendo da quantidade de água precipitada. No entanto, condições críticas de inflamabilidade não são revertidas facilmente. Combustíveis florestais muito secos podem ser umedecidos superficialmente por uma chuva matinal e secarem rapidamente, voltado a se tornarem inflamáveis durante a tarde (Schroeder e Buck, 1970; Pyne, 1984; Soares, 1985).

Ao se avaliar o efeito da precipitação sobre o potencial de propagação do fogo em uma região, é necessário levar em consideração não apenas a quantidade de chuva, mas também sua distribuição estacional. Duas regiões com a mesma precipitação total anual podem apresentar características completamente diferentes com relação a risco de incêndios. Se a distribuição da chuva é uniforme durante todo o ano, sem uma estação seca definida, o potencial de ocorrência e propagação de incêndios é bem menor do que, por exemplo, o potencial de uma região em que a estação chuvosa seja concentrada em alguns meses, com longos períodos de estiagem durante outros meses. A distribuição da precipitação é, portanto, fator fundamental na definição do início, término e duração das estações de alto potencial de incêndio (Schroeder e Buck, 1970; Pyne, 1984; Soares, 1985).

Segundo Santos et al. (2006), os incêndios em vegetação podem provocar prejuízos importantes ao ambiente, como os danos à fauna e à flora, às pessoas, inclusive com perdas de vida, além de consequências econômicas consideráveis. Segundo Gill (2002), o fogo pode conduzir à extinção espécies endêmicas, que crescem muito lentamente e sem estratégias eficientes de reprodução e colonização. Segundo Carvalho e Vilar (2005), a fauna do Parque Nacional de Itabaiana reúne exemplares representativos de espécies endêmicas (típicas da região) e ameaçadas de extinção. A frequente ocorrência de incêndios na região que, porventura, poderia levar espécies endêmicas e já ameaçadas à completa extinção, justifica este trabalho, que teve como objetivo verificar a influência da precipitação na ocorrência de Incêndios Florestais, dentro do Parque Nacional Serra de Itabaiana, identificando os meses mais secos e servindo de subsídio para o desenvolvimento de um plano efetivo de combate a incêndios florestais na área em estudo.

\section{MATERIAL E MÉTODOS}

O Parque Nacional Serra de Itabaiana localiza-se no limite entre os municípios de Itabaiana e Areia Branca, nas latitudes e longitudes aproximadas de $10^{\circ} 40^{\prime} \mathrm{S}$ e $37^{\circ} 25^{\prime} \mathrm{O}$, com aproximadamente $670 \mathrm{~m}$ de altitude, distando cerca de $36 \mathrm{~km}$ da capital Aracaju e $41 \mathrm{~km}$ do litoral (Vicente, 1999). O clima, segundo a Classificação de Köpen, é As': clima tropical com verão seco, com moderado excedente hídrico de inverno e índice hídrico de Thorntwaite (Im) entre -1.3 e -8.8 , ou seja, clima sub-úmido (Sergipe, 1978). 
WHITE, B. L. A.; RIBEIRO, A. S. Análise da precipitação e sua influência na ocorrência de incêndios florestais no Parque Nacional Serra de Itabaiana, Sergipe, Brasil. Ambi-Agua, Taubaté, v. 6, n. 1, p. 148-156, 2011. (doi:10.4136/ambi-agua.180)

Os dados de precipitação diária para o município de Itabaiana - Sergipe, obtidos junto ao Programa de Monitoramento Climático em Tempo Real da Região Nordeste - PROCLIMA, durante o período de 01/01/1999 a 31/12/2009, totalizando 10 anos, ou 3641 dias, foram analisados e separados em 12 grupos de acordo com os meses do ano. Estes grupos, em seguida, foram comparados entre si pelo teste de análise de variância (ANOVA) com o objetivo de verificar a existência de diferença significativa na precipitação de cada mês. A significância utilizada foi de $5 \%$ em todos os casos.

O coeficiente de correlação linear de Pearson, "r” (Equação 1) (Brower et al., 1997) foi estimado entre a precipitação média de cada mês com a quantidade de incêndios registrados dentro do Parque Nacional Serra de Itabaiana, para o respectivo mês. Para testar a significância do " $r$ " encontrado, verificando se a associação entre a precipitação e a quantidade de incêndios existe na população ou resulta meramente de uma casualidade amostral, foi aplicado o teste de significância "t" (Equação 2) (Brower et al., 1997) para o nível de significância de 5\%.

$$
\begin{aligned}
& r=\frac{\sum\left(x_{i}-\bar{x}\right)\left(y_{i}-\bar{y}\right)}{\sqrt{\left(\sum\left(x_{i}-\bar{x}\right)^{2}\right)\left(\sum\left(y_{i}-\bar{y}\right)^{2}\right)}} \\
& t=r \sqrt{\frac{n-2}{1-r^{2}}}
\end{aligned}
$$

em que:

$r=$ Coeficiente de correlação de Pearson

$x_{1}, x_{2}, \ldots, x_{n}=$ Valores da precipitação

$y_{1}, y_{2}, \ldots, y_{n}=$ Valores da ocorrência de incêndios

$\bar{X}=$ Média aritmética da precipitação

$\bar{y}=$ Média aritmética da ocorrência de incêndios

$t=$ Teste de significância

$n=$ Número de pares de escores

Os dados relativos à ocorrência de incêndios dentro do Parque Nacional Serra de Itabaiana foram obtidos junto à equipe do IBAMA, também para o período de 01/01/1999 à $31 / 12 / 2008$.

\section{RESULTADOS E DISCUSSÃO}

Durante os 10 anos de análise (1999-2008), a precipitação média anual foi de $1289 \mathrm{~mm}$, com valor máximo no ano de 2006 (1482 mm) e mínimo em 2007 (1040 mm) (Figura 1). Os valores estão um pouco abaixo da média para a região do litoral do Nordeste do Brasil, que segundo Reboita et al. (2010) é de $1500 \mathrm{~mm} / \mathrm{ano}$. 
WHITE, B. L. A.; RIBEIRO, A. S. Análise da precipitação e sua influência na ocorrência de incêndios florestais no Parque Nacional Serra de Itabaiana, Sergipe, Brasil. Ambi-Agua, Taubaté, v. 6, n. 1, p. 148-156, 2011. (doi:10.4136/ambi-agua.180)

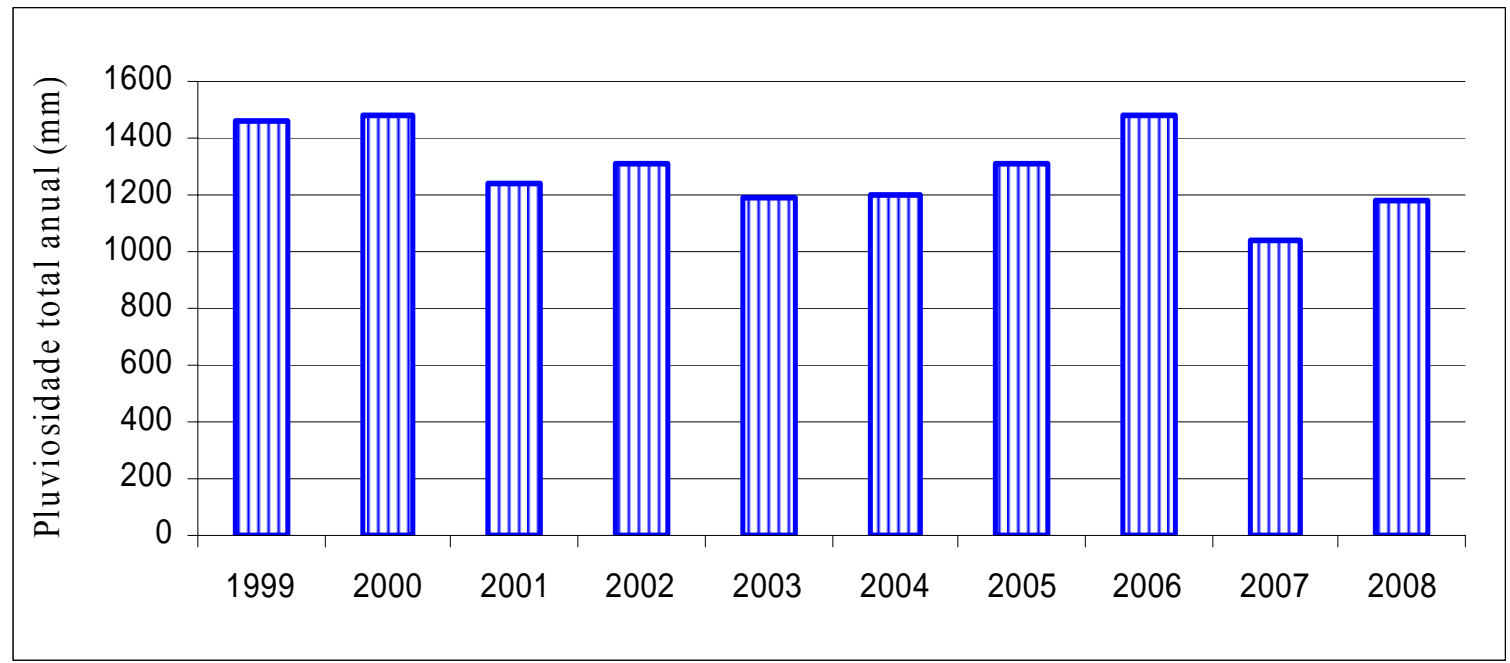

Figura 1. Pluviosidade total anual para o município de Itabaiana (SE) de 1999 a 2008.

O mês de maio apresentou maior quantidade de precipitação e maior desvio padrão, enquanto o mês de dezembro apresentou os menores valores. Para o mesmo período, foram registrados 37 incêndios florestais de acordo com o IBAMA-SE, sendo os meses de janeiro e fevereiro os que apresentaram uma maior quantidade de registros (Tabela 1).

Tabela 1. Valores mensais da precipitação para o município de Itabaiana, Sergipe; e do registro total de incêndios para o respectivo mês, dentro do Parque Nacional Serra de Itabaiana, ambos para o período de 01/01/1999 a 31/12/2008.

\begin{tabular}{l|ccc|c|c}
\hline \multicolumn{1}{c|}{ Mês } & $\begin{array}{c}\text { Total de } \\
\text { dias }\end{array}$ & $\begin{array}{c}\text { Precipitação total } \\
\text { 10 anos (mm) }\end{array}$ & $\begin{array}{c}\text { Precipitação média } \\
\text { diária (mm) }\end{array}$ & $\begin{array}{c}\text { Desvio Padrão } \\
\text { (mm) }\end{array}$ & $\begin{array}{c}\text { Registro total } \\
\text { de incêndios }\end{array}$ \\
\hline Jan. & 309 & 804,6 & 2,60 & 6.79 & 8 \\
Fev. & 282 & 808,92 & 2,87 & 6.67 & 8 \\
Mar. & 309 & 824,88 & 2,67 & 5.76 & 7 \\
Abr. & 299 & 1270,55 & 4,25 & 6.97 & 0 \\
Mai. & 309 & 2118,51 & 6,86 & 11.84 & 0 \\
Jun. & 299 & 1905,9 & 6,37 & 8.73 & 1 \\
Jul. & 309 & 1657,39 & 5,36 & 6.69 & 0 \\
Ago. & 309 & 1262,96 & 4,09 & 5.44 & 0 \\
Set. & 299 & 723,43 & 2,42 & 4.51 & 2 \\
Out. & 309 & 668,09 & 2,16 & 6.55 & 2 \\
Nov. & 299 & 470,2 & 1,57 & 5.84 & 2 \\
Dez. & 309 & 334,02 & 1,08 & 3.17 & 7 \\
\hline
\end{tabular}

Fonte: PROCLIMA; IBAMA-SE.

Aplicando-se o teste da Análise de Variância, verificou-se que, no período correspondente, a quantidade de precipitação entre os meses foi significativamente diferente entre si $\left(F=22,24, p=1,41 \times 10^{-44}\right)$ e evidenciou-se a presença de quatro grupos distintos (Figura 2). 
WHITE, B. L. A.; RIBEIRO, A. S. Análise da precipitação e sua influência na ocorrência de incêndios florestais no Parque Nacional Serra de Itabaiana, Sergipe, Brasil. Ambi-Agua, Taubaté, v. 6, n. 1, p. 148-156, 2011. (doi:10.4136/ambi-agua.180)

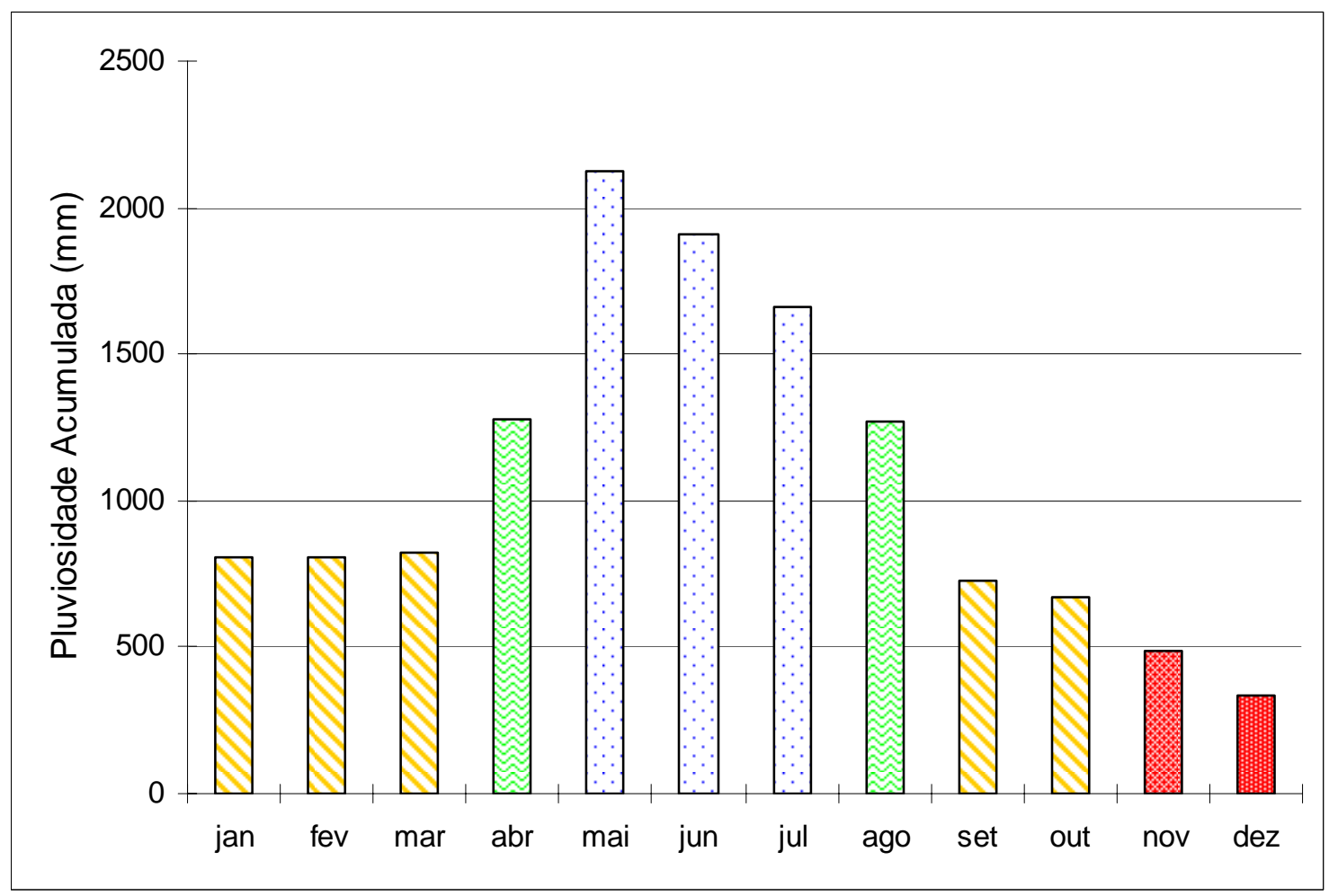

Figura 2. Precipitação mensal acumulada no período de 01/01/1999 a 31/12/2008, para o município de Itabaiana - Sergipe. Os grupos indicam os meses que não tiveram precipitação significativamente diferente entre si, de acordo com a Análise de Variância.

O primeiro grupo foi formado pelos meses com maior precipitação (maio, junho e julho). De acordo com o teste ANOVA, esses meses diferiram significativamente dos outros meses, mas não foram significativamente diferentes entre si $(\mathrm{F}=2,12, \mathrm{p}=0,12)$. Os respectivos meses tiveram uma precipitação média diária $\geq 5,36 \mathrm{~mm}$.

O segundo grupo foi formado pelos meses agosto e abril. Esses meses diferiram significativamente dos outros meses, mas não tiveram diferença significativa entre si $(\mathrm{F}=$ $0,12, p=0,73)$. A precipitação média diária desses meses foi $\geq 4,09 \mathrm{~mm}$ e $\leq 4,3 \mathrm{~mm}$.

O terceiro e maior grupo foi formado pelos meses de janeiro, fevereiro, março, setembro e outubro. Esses meses diferiram significativamente dos outros grupos, mas não diferiram significativamente entre si $(\mathrm{F}=1,56, \mathrm{p}=0,17)$. Os respectivos meses tiveram precipitação média diária $\geq 2,16 \mathrm{~mm}$ e $\leq 2,87 \mathrm{~mm}$.

Os meses de novembro e dezembro diferiram significativamente de todos os outros grupos, mas não diferiram significativamente entre si $(F=2,16, p=0,14)$. Foram os meses mais secos do ano com precipitação média diária $\leq 1,57 \mathrm{~mm}$.

Os dados de precipitação obtidos neste trabalho são similares aos resultados obtidos por Molion e Bernardo (2002) os quais afirmam que a faixa costeira do Nordeste (até $300 \mathrm{~km}$ do litoral), que se estende do Rio Grande do Norte ao sul da Bahia, também conhecida como Zona da Mata, apresenta um regime pluviométrico distinto de outras regiões brasileiras, sendo o período mais chuvoso de abril a julho, com o pico de chuvas em maio. Segundo Reboita et al. (2010) esse regime é diferente do encontrado na maior parte do Brasil (região norte, centro-oeste e sudeste), onde os totais pluviométricos são máximos no verão e mínimos no inverno devido ao sistema de monção.

Já analisando os dados de registro de incêndios florestais dentro do Parque Nacional Serra de Itabaiana (Tabela 1), percebe-se uma maior incidência dos incêndios nos meses de verão: dezembro, janeiro e fevereiro, que juntos representaram $62,2 \%$ do total de ocorrências, e uma menor ocorrência nos meses de inverno: junho, julho e agosto, que juntos, representaram apenas $2,7 \%$ do total de ocorrências. Soares (1988), analisando o perfil dos 
WHITE, B. L. A.; RIBEIRO, A. S. Análise da precipitação e sua influência na ocorrência de incêndios florestais no Parque Nacional Serra de Itabaiana, Sergipe, Brasil. Ambi-Agua, Taubaté, v. 6, n. 1, p. 148-156, 2011. (doi:10.4136/ambi-agua.180)

incêndios florestais no Brasil de 1984 a 1987, afirma que o período em que ocorreu uma maior quantidade de incêndios foi entre os meses de agosto a novembro. Já Soares e Santos (2002), analisando o perfil dos incêndios florestais no Brasil de 1994 a 1997, definiram que a principal estação de incêndios no país é de julho a novembro, quando ocorreram $79,2 \%$ dos incêndios, correspondendo a $98,6 \%$ da área atingida. Segundo os mesmos autores, o mês de agosto (último mês do inverno) foi o mês com maior ocorrência de incêndios durante o período estudado, e os estados de Minas Gerais, São Paulo, Paraná e Rio Grande do Sul contribuíram, respectivamente, com a maior quantidade de registro de incêndios. Santos et al. (2006), ao analisarem o perfil dos incêndios florestais em áreas protegidas no Brasil de 1998 a 2002, obtiveram dados similares, com a estação de incêndios de junho a outubro, totalizando $68,87 \%$ do número de ocorrências, o que representou $90,76 \%$ das áreas queimadas.

Tal diferença entre um maior número de incêndios no verão para o Parque Nacional Serra de Itabaiana e no inverno para a maioria do território brasileiro se deve a um regime hídrico peculiar na área estudada, que apresenta um clima tropical com verão seco e inverno chuvoso. Considerando-se a pequena proporção do território brasileiro com essas características climáticas (Zona da Mata), compreende-se o porquê dos estudos feitos em nível nacional definirem os meses de inverno como nos que mais ocorrem incêndios florestais.

O coeficiente de correlação de Pearson e o teste de significância " $t$ " entre a precipitação média diária e a ocorrência de incêndios florestais dentro do Parque Nacional Serra de Itabaiana, para o período entre janeiro de 1999 a janeiro de 2008, demonstraram uma correlação negativa e significativa $(\mathrm{r}=-0,61, \mathrm{p}=0,03)$ (Figura 3).

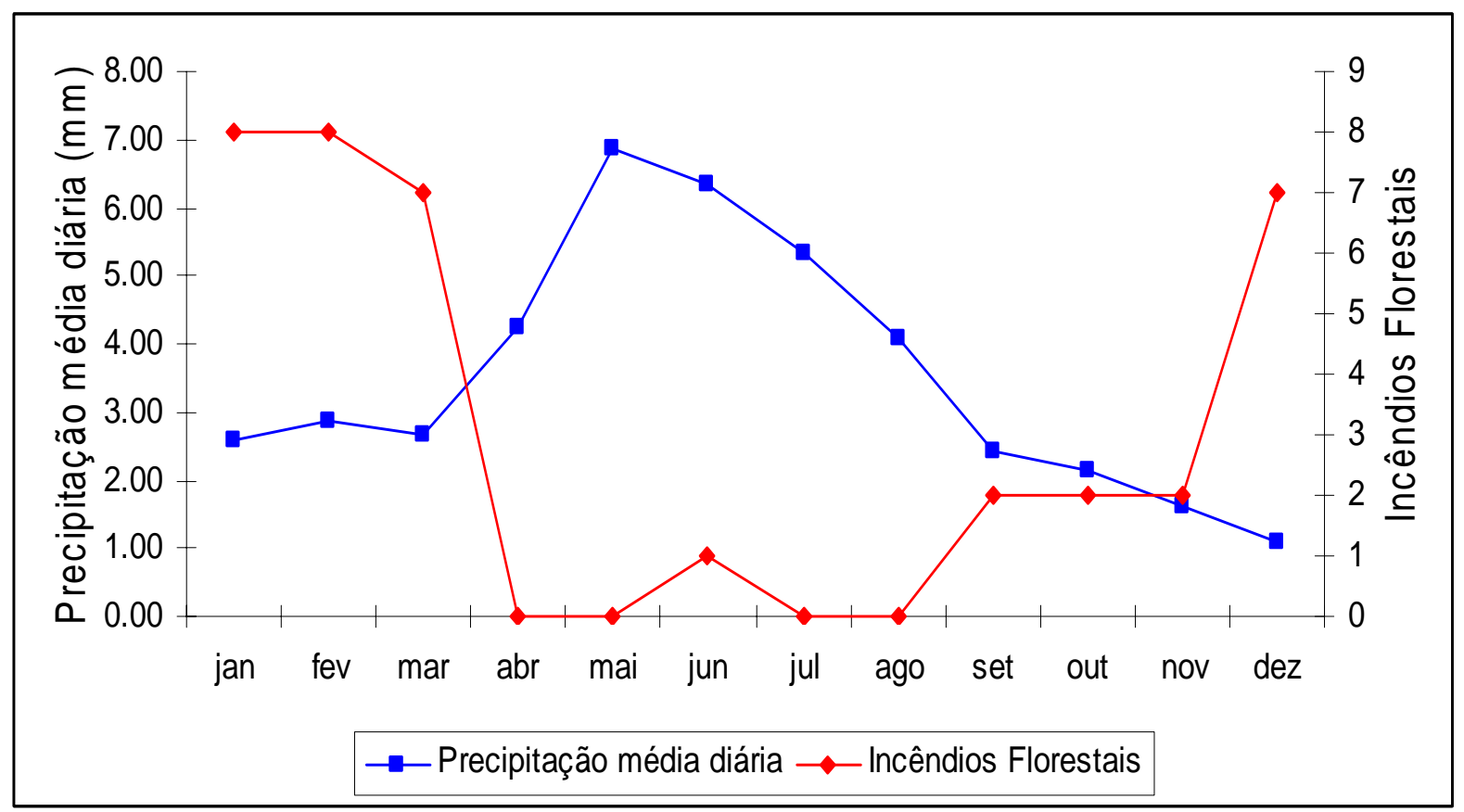

Figura 3. Correlação entre a precipitação média diária e a quantidade de incêndios registrados de acordo com os meses do ano entre 01/01/1999 e 31/12/2008.

Os dados obtidos neste trabalho estão de acordo com diversos estudos acerca da ocorrência de incêndios florestais (e.g., Soares, 1985; Pyne, 1984, Schroeder e Buck, 1970; Nilton et al., 2006; Soares e Batista, 2007; White, 2010), em que todos afirmam que a precipitação é um fator fundamental na redução do potencial de ocorrência de incêndios florestais. Os respectivos autores determinam a estação seca como a época em que mais ocorrem os incêndios. 
WHITE, B. L. A.; RIBEIRO, A. S. Análise da precipitação e sua influência na ocorrência de incêndios florestais no Parque Nacional Serra de Itabaiana, Sergipe, Brasil. Ambi-Agua, Taubaté, v. 6, n. 1, p. 148-156, 2011. (doi:10.4136/ambi-agua.180)

Entretanto, apesar da correlação significativa, percebe-se, pela categorização dos meses, que os meses mais secos: novembro e dezembro, não foram necessariamente os meses com maior ocorrência de incêndios florestais na área estudada. Uma possível explicação para o fato pode ser dada com base na premissa de que os combustíveis florestais extremamente secos podem ser umedecidos superficialmente por chuvas pequenas e rápidas, e secarem rapidamente ao longo do dia, voltando a apresentar alta facilidade de entrar em ignição (Pyne, 1984; Soares, 1985; Soares e Batista, 2007). Ciente de tal fato e, levando-se em conta que em janeiro, fevereiro e março os combustíveis estão extremamente secos devido ao grande déficit hídrico durante os meses de novembro e dezembro, uma possível hipótese seria que um pequeno acréscimo na quantidade de chuva nesses meses, em relação aos de novembro e dezembro, não seria suficientemente grande para umedecer o material combustível, que continuaria seco e com alta probabilidade de entrar em processo de ignição.

Também é necessário levar em conta que outros fatores que influenciam a ocorrência de incêndios florestais: temperatura, umidade relativa do ar e velocidade do vento, não foram analisados. Segundo Soares (1998) e Freedman (1989), a temperatura e umidade relativa do ar são variáveis que influenciam no teor de umidade do material combustível, podendo afetar diretamente sua facilidade de entrar em ignição. Onigemo (2006), ao avaliar a eficiência dos índices de perigo de ocorrência de incêndios no Pantanal - MS, chegou à conclusão de que além da precipitação, fatores como a temperatura e umidade relativa do ar, devem ser considerados ao se avaliar a previsão de risco de incêndio. Já Torres (2006), ao analisar a ocorrência de incêndios florestais em Juiz de Fora - MG, concluiu que a umidade relativa do ar apresenta uma maior influência nas ocorrências de incêndios do que o total anual de precipitação.

\section{CONCLUSÕES}

Por meio da análise de variância da precipitação para o município de Itabaiana, os meses de maio, junho e julho foram agrupados como os meses com maior precipitação, enquanto os meses de novembro e dezembro como os de menor. Já, de acordo com os dados fornecidos pelo IBAMA, ocorreu uma maior quantidade de incêndios durante o verão $(62,2 \%)$, enquanto no inverno apenas uma ocorrência foi registrada, representando 2,7\% do total. Embora na maior parte do Brasil os incêndios florestais ocorram principalmente durante o inverno, a sua ocorrência sempre está associada a períodos secos.

Apesar da correlação significativa entre a variável precipitação média diária e a quantidade de incêndios registrados de acordo com os meses do ano, percebe-se que nos meses em que ocorreu uma menor quantidade de precipitação não foram os com maior registro de incêndios. Novos estudos devem ser realizados para verificar a hipótese de que a maior quantidade de chuva nos meses de janeiro, fevereiro e março, em comparação à chuva dos meses novembro e dezembro, não é suficientemente grande para umedecer o material combustível, que permanece seco e com alta facilidade de entrar no processo de ignição.

Com os dados obtidos neste trabalho, as autoridades responsáveis pelo combate ao fogo no Parque Nacional Serra de Itabaiana podem aprimorar o serviço de combate a incêndios florestais, definindo maior contingente de brigadistas e ampliando as ações de educação ambiental nos meses mais críticos do ano.

\section{AGRADECIMENTOS}

Ao Deutscher Akademischer Austausch Dienst (DAAD) pela bolsa concedida ao primeiro autor, e a Marleno Costa do IBAMA-SE pela disponibilidade dos dados. 
WHITE, B. L. A.; RIBEIRO, A. S. Análise da precipitação e sua influência na ocorrência de incêndios florestais no Parque Nacional Serra de Itabaiana, Sergipe, Brasil. Ambi-Agua, Taubaté, v. 6, n. 1, p. 148-156, 2011. (doi:10.4136/ambi-agua.180)

\section{REFERÊNCIAS}

BROWER, J. E.; ZAR, J. H.; VON ENDE C. N. Field and laboratory methods for general ecology. 4. ed. Iowa: W.C. Brown, 1997. 194p.

CARVAlHO, C. M.; VILAR, J. C. Parque Nacional Serra de Itabaiana: levantamento da Biota. Aracaju: IBAMA, Biologia Geral e Experimental; UFS, 2005. 124p.

FREEDMAN, B. Enviromental ecology: the impacts of pollution and other stresses on ecossystem structure and funtion). San Diego: Academic Press, 1989. 300p.

GILL, A. M. How fires affect biodiversity. In: Fire and Biodiversity: the effects and effectiveness of fire management. 2002. (Biodiversity, 8). Disponível em: $<$ http://www.anbg.gov.au/fire_ecology/fire-and-biodiversity.html\#INT $>$. Acesso : 2 nov. 2007.

MOLION, L. C. B.; BERNARDO, S. O. Uma revisão da dinâmica das chuvas no nordeste brasileiro. Revista Brasileira de Meteorologia, São Paulo, v. 17, n. 1, p. 1-10, 2002.

NILTON, C. F.; MERLO, D. A.; MEDEIROS, M. B. de. Ocorrência de incêndios florestais no Parque Nacional da Chapada dos Veadeiros, Goiás. Ciência Florestal, Santa Maria, v. 16, n. 2, p. 153-161, 2006.

ONIGEMO, A. E. Avaliação de índices de risco de incêndio em áreas com predominância de Gramíneas Cespitosas na sub-região da Nhecolândia, Pantanal, MS. 2006. 142f. Tese (Doutorado em Ecologia) - Universidade Federal de Mato Grosso do Sul, Campo Grande, 2006.

PYNE, S. J. Wildland fire: fire management in the United States. New York: Wiley \& Sons, 1984. 769p.

REBOITA, M. S.; GAN, M. A.; ROCHA, R. P. da; AMBRIZZI, T. Regimes de precipitação na América do Sul: uma revisão bibliográfica. Revista brasileira de meteorologia, São Paulo, v. 25, n. 2, p. 185-204, 2010.

SANTOS, J. F.; SOARES, R. V.; BATISTA, A. C. Perfil dos incêndios florestais no Brasil em áreas protegidas no período de 1998 a 2002. Revista Floresta, Curitiba, v. 36, n. 1, p. 93-100, 2006.

SCHROEDER, M. J.; BUCK, C. C. Fire weather: A guide for application of meteorological information for forest fire control operations. Washington: US. Forest Service, 1970. 229 p. (Agriculture Handbook, 360).

SERGIPE. Projeto básico para a implantação da Estação Ecológica Serra de ItabaianaSE. Aracaju: Governo do Estado, 1978.

SOARES, R. V. Incêndios florestais: controle e uso do fogo. Curitiba: FUPEF, 1985. 213p.

SOARES R. V. Perfil dw incêndios florestais no Brasil de 1984 a 1987. Revista Floresta, Curitiba, v. 18, n. 1/2, p. 94-121, 1988.

SOARES, R. V. Desempenho da "Fórmula de Monte Alegre": índice brasileiro de perigo de incêndios florestais. Cerne, Lavras, v. 4, n. 1, p. 87-99, 1998.

SOARES, R. V.; BATISTA, A. C. Incêndios florestais: controle, efeitos e uso do fogo. Curitiba, 2007. 264 p. 
WHITE, B. L. A.; RIBEIRO, A. S. Análise da precipitação e sua influência na ocorrência de incêndios florestais no Parque Nacional Serra de Itabaiana, Sergipe, Brasil. Ambi-Agua, Taubaté, v. 6, n. 1, p. 148-156, 2011. (doi:10.4136/ambi-agua.180)

SOARES R. V.; SANTOS J. F. Perfil dos incêndios florestais no Brasil de 1994 a 1997. Revista Floresta, Curitiba, v. 32, n. 2, p. 219-232, 2002.

TORRES, F. T. P. Relações entre fatores climáticos e ocorrências de incêndios florestais na cidade de Juiz de Fora (MG). Caminhos da Geografia, Uberlândia, v. 7, n. 18, p. 162$171,2006$.

VICENTE, A. Levantamento florístico de um fragmento florestal na Serra de Itabaiana - Sergipe. 1999. 113f. Dissertação (Mestrado em Botânica) - Universidade Federal Rural de Pernambuco, Recife, 1999.

WHITE, B. L. A. Incêndios florestais no Parque Nacional Serra de Itabaiana - Sergipe. 2010. 142f. Dissertação (Mestrado em Desenvolvimento e Meio Ambiente) - Programa Regional em Desenvolvimento e Meio Ambiente, Universidade Federal de Sergipe, São Cristóvão, 2010. 